\title{
One size doesn't fit all: rethinking approaches to continuing professional development in technology enhanced learning
}

\author{
Martin Compton, Timos Almpanis \\ University of Greenwich
}

\section{Introduction}

In a prescient book, Tony Bates (2000) stated that students would reject universities which refused - or were unable - to integrate technology into teaching and learning. To fail to integrate it has long been unthinkable; its deployment has been unavoidable (Donnelly and O'Rourke, 2007). However, the pace of change, the embedding of technology and the approaches taken have not been as swift or successful as many would have hoped. Analyses of data from National Student Surveys (NSS) suggest that the negative views of students about assessment and feedback might be accounted for by failure to exploit the potential of technology (Cook and Jenkins, 2010). More recently, whilst $80 \%$ of Higher Education (HE) students reported reliance on their Virtual Learning Environment (VLE), only $40.8 \%$ said that they enjoyed VLEs' collaborative features and only half stated that their programmes of study were preparing them adequately for digital workplaces (Newman and Beetham, 2017).

There is no doubt that Higher Education Providers (HEPs) have invested in technological infrastructure for teaching and learning, as well as in what must often seem like an army of learning technologists to support and promote the use of various learning platforms. Some of the systems' licences cost tens of thousands pounds per annum. VLEs are now commonplace in UK HEPs and their use by lecturers is increasingly prescribed.

Furthermore, the vast majority of Institutions have deployed IT solutions for the electronic management of assessment (EMA) which includes online submission and online marking. Lately, lecture capture systems have become increasingly popular as well (Walker et al., 2016). Whilst the above centrally-deployed systems have been used by many staff, they are often used for their administrative benefits rather than to transform teaching and learning. For instance, in the majority of cases, the VLE has been used largely as a content repository and EMA practices have been implemented for their administrative benefits and for convenience, as they allow students to submit their work (and tutors to mark it) from anywhere in the world.

Many HEPs are aware of the potential growth of online, distance (and often shorter) courses and programmes using such approaches as Massive Open Online Courses (MOOCs) and/or strategies that seek to push mobile learning and 'Bring your own device' (BYOD). However, Paul Feldman, Chief Executive of Jisc (cited in Newman and Beetham, 2017, p.5), says that "some providers still need to do more to get the basics right - including guaranteeing decent wifi provision across campuses and continuing access to desktop computers". Within this evolving and often discordant technology enhanced learning (TEL) landscape, one aspect that is also fraught with difficulty is the way new technologies and technological initiatives are deployed and supported, especially in terms of continuous professional development (CPD) for staff with lecturing or other student-facing roles. Institutional technology is often 


\section{Articles}

introduced to lecturers with standardised, one-size-fits-all training sessions which focus on the technological functions rather than pedagogy (see Figure 1 below). In our current roles as educational developers, both authors have lecturer education responsibilities which include the use, promotion, modelling and support of technologies for teaching, learning and assessment. Our previous work in teacher education and learning technology, and with a range of post-1992 HEPs, suggests that this is a sector-wide need. This experience has given us both the opportunity to see evidence of missed opportunities, misalignment of technology with training, a disconnect between the technological tools and pedagogy and the persistence of forms of the didactic, tool-focused training that is more transmissive than transformative. One consequence is that it fails to engender the hoped-for spike in the use of such tools, let alone innovative and creative uses of them. Despite its ability to improve the quality of teaching and learning and, in our NSS-sensitive world, such essentials as rapidity of feedback, there remains an apparent reluctance to change established academic practices at the anticipated/desired rate, to the intended scale or by the type of technology used.

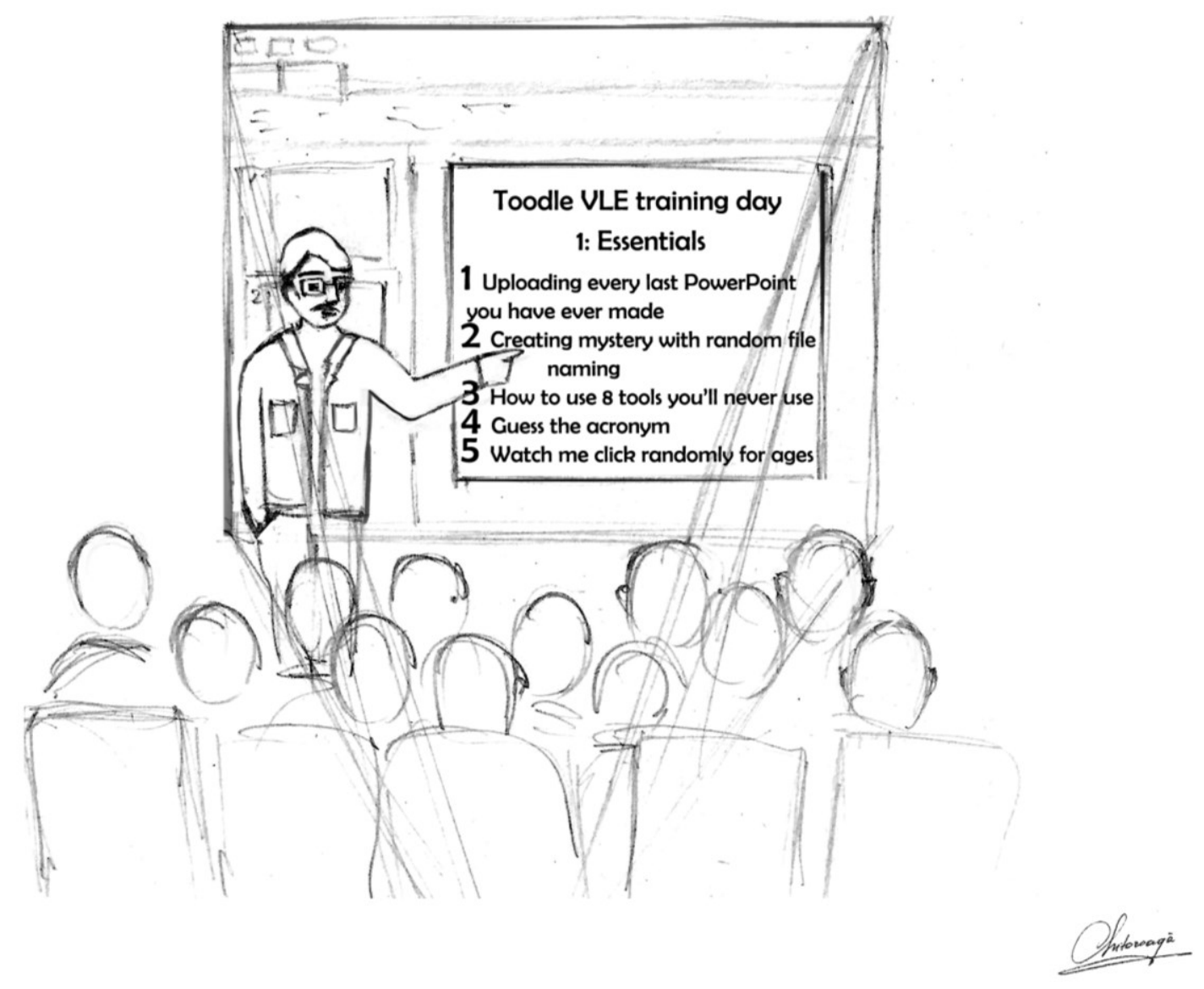

(C) Artist: Cristina Chitoroaga (First-year BA Hons Graphic and Digital Design student at the University of Greenwich)

Figure 1: One size fits all: a training day horror

We have discovered that we have sought to tackle this in similar ways. We both favour the use of cloud-based educational and productivity applications (or 'apps') where there is an identified need - for lecturer or student - or where existing tools (for example, the 
collaborative tools in VLEs that the majority of students do not enjoy) are too clunky, unintuitive or inadequate. We also favour a re-focus - away from the 'tool' - which instead places purpose and pedagogy at the focal point. An example of this would be sessions where colleagues are invited to consider the concept of the 'advance organiser' and are first shown a range of technological approaches to creating advance organisers. They then choose one they feel may best suit their cohorts, their needs and their technological 'comfort zone' and produce an 'artefact' that can be trialled with their students. Step-by-step training, how-to guides and at-the-elbow 'click here, click there' training are replaced by choice, discovery, collaboration and available support if required. On the formal training programmes that we offer academics, we model a selection of tools as exemplars and present them as options for completion of individual or collaborative assessments. We make frequent use of such methods as screencasts, podcasts, interactive video content and curated material; participants often ask us about these and how they might apply them in their own contexts. By these means, we are suggesting and providing alternative approaches to using technology for teaching and learning that are needs-focused, more likely to be individualised and helpful for recognising and addressing some recurring problems. This contrasts with the standardised training characterised in Figure 2 below. Integrating relatively easy-to-use 'quick win' apps into the VLE increases interest in using them to enhance the look, feel and effectiveness of the courses on the VLE. In this paper, we detail some of the problems and rationalise further the approach we take, arguing that we are more likely to effect change in technology-use culture if we eschew as default the one-size-fits-all approach, with its emphasis on institution-wide systems and compliance.

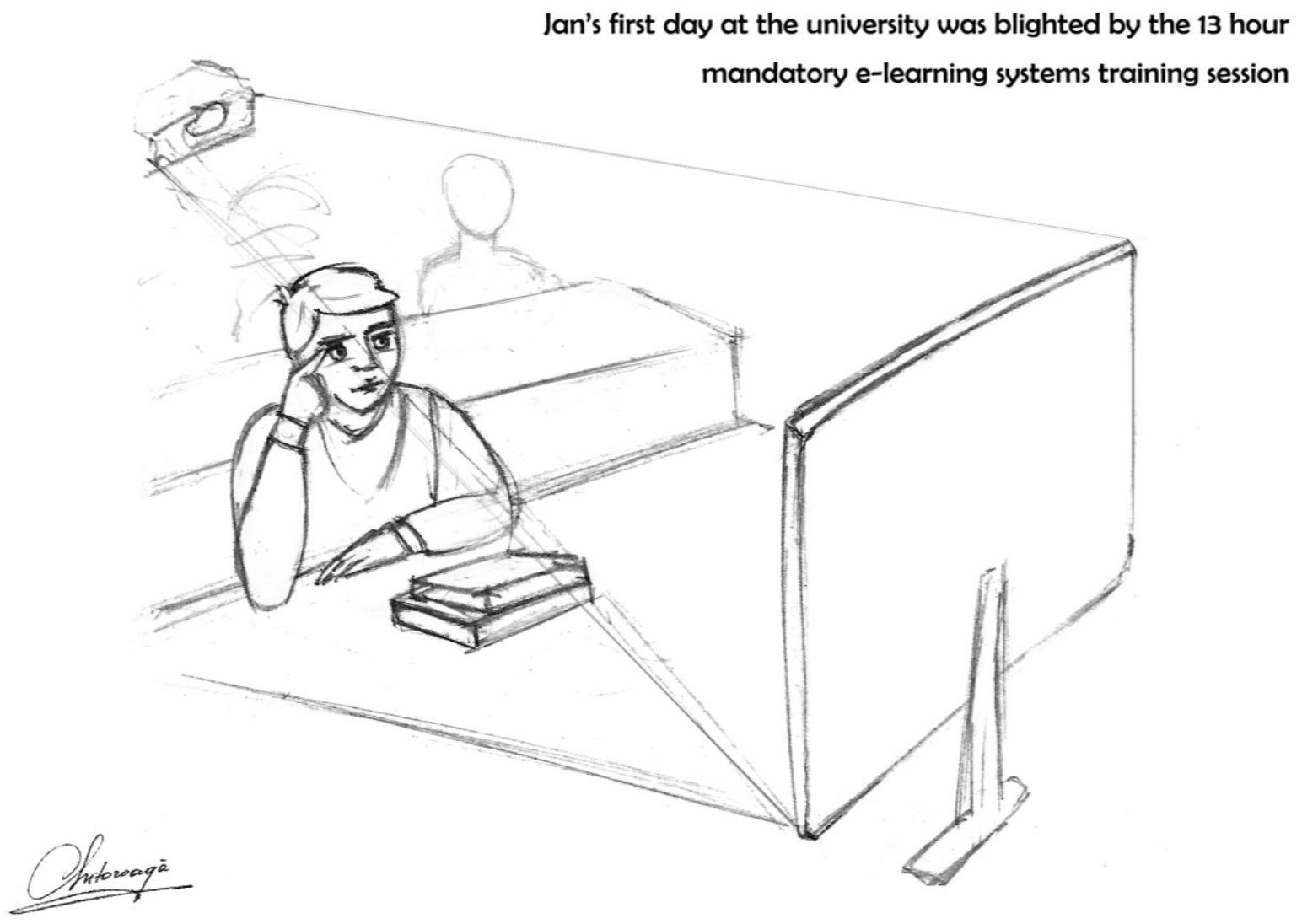

(c) Artist: Cristina Chitoroaga (First-year BA Hons Graphic and Digital Design student at the University of Greenwich)

Figure 2: The thrill of the mandatory e-learning training 
We also argue that, to challenge the apparent reluctance to embed technology, there is potential in rethinking the strategic approach to the tools used and the ways they are introduced and supported. We suggest that free or freemium ${ }^{1}$ cloud-based tools and mobile apps have the potential to engage lecturers and thereby enhance teaching, learning and assessment; they would complement, and encourage use of, the established institutional learning technology platforms.

\section{Resistance and barriers}

Given the impetus for integrating technology into learning, teaching and assessment, the internal and external drivers of it and the degree of investment in it, why do most of us not work in technology utopias, surrounded by adept lecturers comfortably using a range of bespoke productivity tools to enhance that teaching, learning and assessment in dynamic, fluid and innovative ways? A cynical view might be that academics are notoriously conservative and have to be dragged, kicking and screaming, into the digital age; indeed, when it comes to the use of learning technologies in HE, staff reluctance and resistance reportedly constitute one of the main barriers to the widespread adoption of TEL by teaching staff (Almpanis, 2015a). Yet there are logical and reasoned arguments that might better explain this reluctance, inability or scepticism. In relation to elementary education (though the arguments have resonance at the other levels of education), Rowan (2014) cites fears about medical and emotional dangers, 'detachment from humanity', dubious cost benefits, neglect of 'basics' and 'unproven benefit'. This continuing debate "is compounded by the fact that there is very little reliable, original pedagogic research and evaluation evidence" (Anderson, 2007, p. 32) - a fact that, ten years on, is often an argument for resistance.

According to Rogers' (2003) 'Diffusion of Innovations' model, new ideas, if they are to spread, need communication channels, time and a social system. In this process, just a few people are the innovators, followed initially by the early adopters. Next, the early majority adopts the innovation, followed by the late majority. Finally, there are the 'laggards', who fall behind, either because the innovation is passing them by or because they are reluctant to change.

When it comes to the use of technology in education, reasons behind this 'laggardliness' include pressures on staff time, lack of digital skills and, more importantly in the context of our argument, lack of pedagogical understanding of the ways technology can be used as part of a different teaching approach (Almpanis, 2015a). Time and financial costs - in set-up, maintenance and encouraging participation (Hughes and Kidd, not dated) - are common barriers, both individually and institutionally. Lack of appropriate resources (Attwell and Hughes, 2010) and the (physical and virtual) location of those resources (Romiszowski, 2004; Daly, Pachler and Pelletier, 2009; Attwell and Hughes, 2010) have also been frequently-reported impediments, as, too, have reliability of equipment and time commitments (Butler and Sellborn, 2009). Romiszowski (2004) argues that it is not the technology itself, but the lack of both institutional understanding and of training that lead to failure. Our own experiences do seem also to confirm that current HE budget constraints are a major impediment to completely comprehensive staff acceptance of - and capability to apply - technological strategies in learning and teaching.

\footnotetext{
${ }^{1}$ Freemium: a business model where basic services are free of charge while more advanced features must be paid for.
} 
An extensive literature review (Atwell and Hughes, 2010) on pedagogic approaches to using technology in the classroom makes it clear that pedagogic benefits still outweigh the issues cited above if approach, training and investment support their use. Those infrastructural and policy impediments are largely beyond our direct sphere of influence, but CPD, from one-off sessions to full lecturer-development programmes, is central to our roles in the Educational Development Unit. Our roles require us to deploy technology and model pedagogically its effective use. Through personal and professional interests, we are exposed to a range of approaches and tools that sit outside such institutional systems as the VLE.

The following section looks at how CPD in the application of learning technologies can form the basis for positive changes and new directions.

\section{CPD in the use of learning technologies}

One of the most fundamental issues in much of the dominant HEP CPD in the use of learning technologies is the disconnect between pedagogy and technology. This is a frequent refrain in the two most comprehensive educational technology reviews (Daly, Pachler and Pelletier, 2009; Attwell and Hughes, 2010), where acknowledgement of the apparently impressive extent of technology-based training is counterpointed with the observation that too much of it is skills-focused and fails to address pedagogy, let alone subject specificity or teacher dispositions. Attwell and Hughes (2010) argued that, considering the emphasis placed on improving integration of technology and education, there was "a surprising lack of research on the impact, organisation effectiveness and still less the pedagogy of such professional development" (ibid., p.5). Whilst this has been addressed to an extent in the last few years, it is still far from being comprehensive, consensual or compelling.

The academic evidence and the continuing problems hint at the solutions, however. The issues above suggest that part of the solution might be technology that is easier to use, is cheap and/or free and, above all, saves time or has quick and easy tools (Bitner and Bitner, 2002). Other solutions suggested by the deficits identified could be to: give 'ownership' and make access flexible (Bradshaw et al., 2012; Beetham and Sharpe, 2007); evaluate, trial, show value to engage teachers' interest (Butler and Sellborn, 2002); change entrenched attitudes and beliefs (Hew and Brush, 2007; Guskey, 2002). We share Guskey's (2002) view that teacher behaviours will change only if teacher beliefs are challenged.

In terms of the actual process of CPD, there is a need to have agreed content, ownership of CPD materials and a culture-shift away from teachers having CPD 'done' to them (Bradshaw et al., 2012). Nevertheless, there remains value discord in relation to types of CPD: transformative CPD, which rates informal and collaborative learning highly, is not favoured by key policy-making and managerial stakeholders (Kennedy, 2011). 


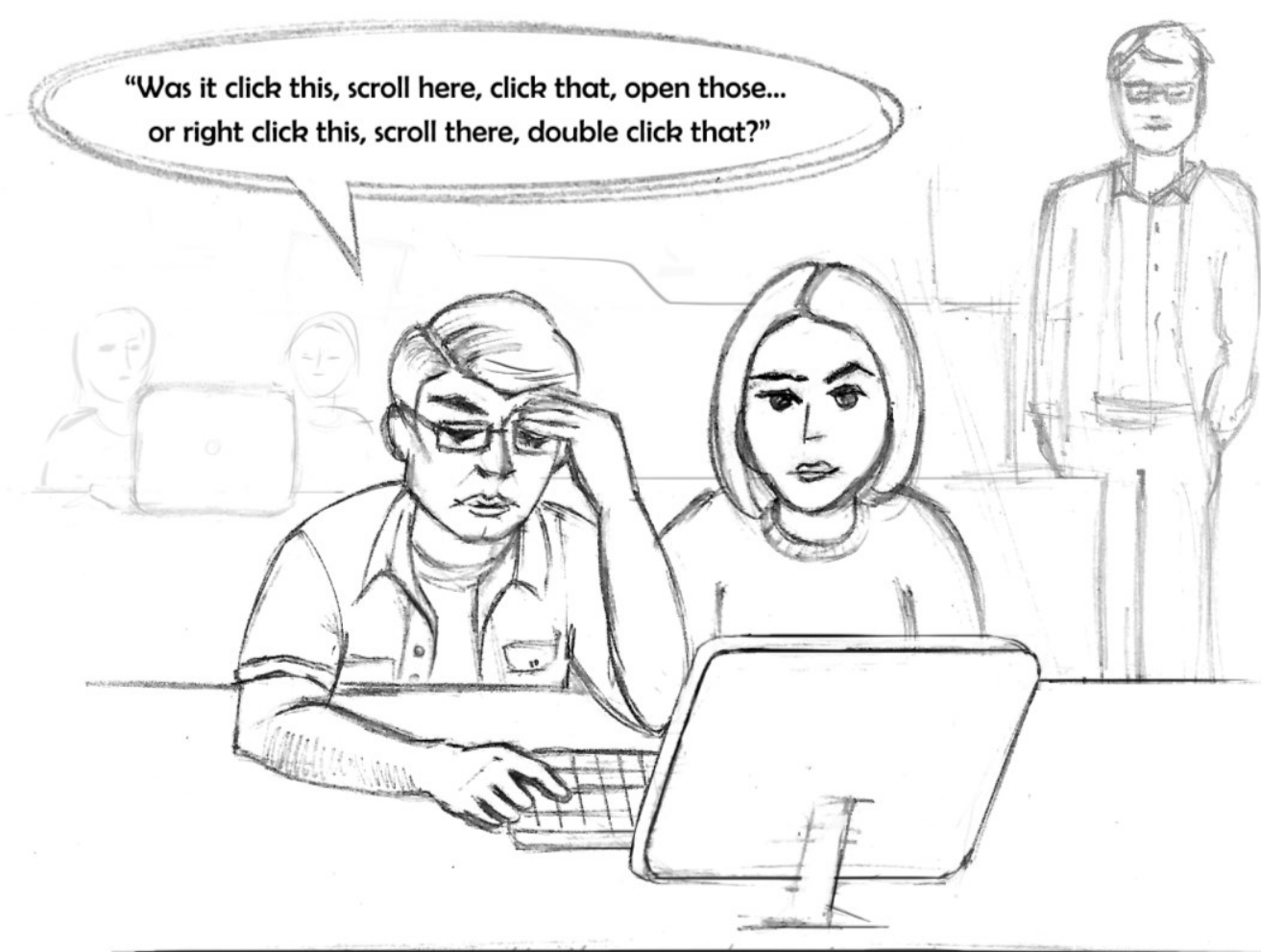

() Artist: Cristina Chitoroaga (First-year BA Hons Graphic and Digital Design student at the University of Greenwich)

Figure 3:The do-what-I-do e-learning training model

Embracing the changing role of teachers and providing carefully-planned CPD are essential for effective use of technology in and beyond classrooms (Ackerman and Krupp, 2012; Almpanis 2015b). Multiple models for the implementation of educational technology are needed, as well as innovative approaches to curriculum delivery (Oblinger, 2012). Putting teachers at the heart of technology implementation, in lieu of the tendency towards technology-driven approaches to CPD, is also crucial (Hennessy et al., 2005). The inadequacies of a one-size-fits-all training approach (see Figure 3 above), though this appears to remain the predominant model, are mentioned in most of the analytical literature from the last decade or more (Koehler and Mishra, 2009; Attwell and Hughes, 2010).

Ownership, informal learning, relevance and supported links to pedagogy therefore appear fundamental to achieving the changes desired by all the key policy-making stakeholders. An extensive study (Cordingley et al., 2007) of positive outcome and specialist-led CPD in schools, found that there were commonalities in approach similar to those cited above, though the structures and types of interventions were varied.

Effective CPD is as much about the process as the content (Rodriguez et al., 2003) and needs to be dynamic to reflect the rapidly-changing nature of technology itself (Donnelly and 
O'Rourke, 2007). Koehler and Mishra (2009) argue that that digital technologies are mistakenly considered to be like other technologies used in classrooms, such as whiteboards and pens. However, they are 'protean' (multi-functional), 'unstable' (constantly evolving) and 'opaque' (ibid., p.61) (it's not self-evident how they should be applied) and this means that alternative approaches for teacher development need to be employed.

The changing e-tool landscape - in terms of what tools are available and how innovators are using them for teaching, learning and assessment - will also have impact on sustainable CPD designs. Teachers' already-acquired capabilities in using social media technologies will have an increasing impact on their digital literacy and could be harnessed and focused on pedagogy. A survey, by Ecclesfield et al. (2013, p.10), of over $800 \mathrm{FE}$ practitioners led them to conclude that the factors which define effective education technology interventions are: "good teaching and learning and not uniform use of large centralised technology hosted by the employer" and "training should be aimed at the application of technology".

\section{Cloud tools and apps}

The use of mainstream, institutional and sometimes inflexible platforms has been criticised by the 'Edupunk' movement, whose members advocate a more do-it-yourself approach to technology, by means of free, cloud-based tools (DeSantis, 2012). Their argument is that institutional systems can be used for management and control and they are not fit for purpose, whereas a combination of freely-available tools allows for more flexibility and freedom of choice, providing opportunities for the online community to remain active beyond the strict duration of a course. This also means that students will become more familiar with technologies they might be using already or will use later on in their professional lives, so acquiring real-world experiences and becoming more digitally literate. This approach, of course, would require academic staff who are not only digitally literate but also willing to explore new possibilities for learning.

Whilst we doubt that most academics feel they are in a position to embrace fully the Edupunk ethos, we feel there is much that is inspiring and potentially beneficial when it comes to the integration of technology. There are countless apps designed for cloud-based use and others that work with tablets and smartphones. Many are designed deliberately for the education market, whereas others are better framed as 'productivity' tools that have applications within, but also beyond, education. We have been using, testing, collecting and disseminating these tools for several years. We have established three broad criteria for their use. They need to meet all three to have any chance of proving a utility to some teaching academics:

Are they cloud-based or mobile apps that are free/freemium? Too often, those with purchasing power are 'wowed' at technology exhibitions or other events and persuaded to buy expensive licences without considering training costs or other implications. If the tool/software also requires a download or individual installation, then this adds additional barriers and costs. Trialling and, hopefully, continuing limited use for cloud-based and mobile apps must be free, freemium or advertisement-supported. This allows for a diversity of tool use, precisely aligned where possible to the specific need.

Are they easy to use? One of the perennial problems with technology is that what is easy to an expert learning technologist may seem unintuitive and very difficult to someone who 
does not use technology to the same level. Of course, 'easiness' is a supremely subjective concept, but our benchmark is the Microsoft PowerPoint software: for something to be 'easy', it needs to have a shallower learning curve than that, and, preferably, significantly so.

Are they fit for purpose? Do they fulfil a need that might otherwise not be met by existing technology or do it better? For instance, most VLEs have quizzing tools, can support video upload and have wiki-type collaboration spaces, but a wide range of tools can do these things with greater ease, providing better functionality and integrating (e.g. through linking or embedding) with VLE platforms.

For example, for our own programmes, we use online curation tools to collect and collate our own as well as web-based content (such as YouTube videos) and then embed these resources in our VLE. We estimate that to organise and upload the same amount of material directly in the VLE would take between three to five times longer. We use collaborative cloud-based presentation software embedded in the VLE to provide a single space for cocreated resources. We use cloud-based poll and quiz-authoring tools linked to or embedded in VLE content to encourage interaction and engagement. The authoring of this takes a fraction of the time of the VLE system, is usually more visually appealing and is diverse in format and question-type options. It is sometimes argued that the tracking options are limited, and this may be true with some of the tools we use, but our intention is engagement and formative assessment (as well, of course, in our case, of showing lecturers the range of tools available to them). We also utilise content created with mobile and tablet apps, such as presentation artefacts, animations and interactive media, or create resources that allow for interaction via mobiles and tablets.

The use of these tools has additional benefits. Setting up a student collaboration zone using a VLE tool means that users experience something that has no transferability beyond education settings. VLEs are by definition 'walled gardens' and so, though the online collaboration is there, the wider, future use potential is not. Beyond tools used within or alongside the VLE, we have also shifted from a paid, bespoke e-portfolio system to one that exploits free online cloud storage. It also allows our students (who are our colleagues) to see potential in such use of cloud storage and authoring systems, which many have, in turn, applied to their own context. In all these instances we are overtly focusing on teaching and learning, but, in many ways, conducting technological CPD by stealth. The focus on pedagogy on the programme is underpinned at all stages by the tools and approaches used and this provides a springboard for continual requests for one-to-one, departmental and faculty support in using similar tools and approaches. One example has been the success of the '30 apps' session, which encourages colleagues to consider the potential of a range of cloud and mobile apps before choosing one or two for experimentation and application to their discipline and teaching contexts.

When using open tools, it is important to keep in mind that staff and students develop their conceptual digital capabilities alongside the technical in order to meet their pedagogical needs. As traces of usage in such tools as Twitter and blogs will leave a digital footprint for a very long time, lecturers should emphasise the importance of responsible and professional use of such software, enabling students to have a considered approach and preparing them for the workplace. 


\section{Conclusions}

Institutional systems that support learning still have a place, as they provide a TEL baseline. These systems are modular and integrated to other university systems, such as student records, thus making easy some of the administrative processes in creating an online safe space per course or programme. However, we argue that these spaces can be enhanced and/or spiced up by the use of other cloud-based solutions as and when the lecturer sees fit, on the basis of context and pedagogical needs.

The wide adoption of institutional platforms doesn't necessarily equal effective use. A more blended approach to the tools used might be the way forward. Institutional platforms such as VLEs can still be used as the backbone, but other cloud tools can also be used when they are fitter for purpose.

Whilst training and support for the institutional platforms may continue to be centralised and offered by non-academic staff, knowledge-sharing among educators by means of the pedagogically-effective use of various cloud-based solutions and applications is important too. Our advice is to 'start small, start easy and then build up'. Decision-making in choosing the right tool for each scenario is always required: whilst a discussion forum in the VLE might sometimes look like a safe option for students to express their opinions, a publicly-available blog may provide a more real-world experience to students studying media or journalism, for instance.

We suggest that a blended approach in terms of the tools used in HE is the way forward; the VLE as the learning portal can be the cake but without the icing, cherries and candles: it might be a bit dry and uninspiring! Furthermore, letting lecturers have a little pick at the embellishments may persuade them to try a whole slice voluntarily rather than having it force-fed to them.

\section{Reference list}

Ackerman, A.S. and Krupp, M.L. (2012) 'Five Components to Consider for BYOT/BYOD.' International Association for Development of the Information Society. Available at: http://files.eric.ed.gov/fulltext/ED542652.pdf (Accessed: 26 March 2017).

Almpanis, T. (2015a) Staff development and wider institutional approaches around technology enhanced learning in higher education institutions in the United Kingdom from the heads of e-learning perspective. PhD thesis. Available at: http://eprints.lancs.ac.uk/83741/ (Accessed: 23 October 2017).

Almpanis, T. (2015b) 'Staff Development and Institutional Support for Technology Enhanced Learning in UK universities.' Electronic Journal of E-Learning, 13(5), 379-388. Available at: http://www.ejel.org/volume13/issue5/p379 (Accessed: 23 October 2017). 
Anderson, P. (2007) What is Web 2.0: ideas, technologies and implications for education. Jisc Technology \& Standards Watch. Available at:

http://www.jisc.ac.uk/media/documents/techwatch/tsw0701b.pdf (Accessed: 22 March 2017).

Attwell, G. and Hughes, J. (2010) Pedagogic Approaches to Using Technology for Learning. Available at:

http://webarchive.nationalarchives.gov.uk/20110414152025/http:/www.Iluk.org/wpcontent/uploads/2011/01/Pedagogical-appraches-for-using-technology-literature-reviewjanuary-11-FINAL.pdf (Accessed: 25 March 2017).

Bates, A.T. (2000) Managing technological change. San Francisco: Jossey-Bass.

Beetham, H. and Sharpe, R. (eds.) (2007) Rethinking Pedagogy for a Digital Age. Designing and delivering e-learning. London: Routledge.

Bitner, N. and Bitner, J. (2002) 'Integrating technology into the classroom: Eight keys to success.' Journal of technology and teacher education, 10(1), 95-100. Available at: https://www.learntechlib.org/p/9304/ (Accessed: 13 October 2017).

Bradshaw, P., Twining, P. and Walsh, C.S. (2012) 'The Vital Program: Transforming ICT Professional Development.' American Journal of Distance Education, 26 (2), 74-85. Available at: https://www.tandfonline.com/doi/abs/10.1080/08923647.2012.655553 (Accessed: 11 October 2017).

Butler, D. and Sellbom, M. (2002) 'Barriers to adopting technology for teaching and learning.' Educause Quarterly 2, 22-28. Available at:

https://www.educause.edu/ir/library/pdf/eqm0223.pdf (Accessed: 11 October 2017).

Cook, J. and Jenkins, V. (2010) Getting Started with e-Assessment. Bath: University of Bath. Available at: http://opus.bath.ac.uk/17712/1/Getting started with eassessment 14Jan2010.pdf (Accessed: 11 September 2017).

Cordingley, P., Bell, M., Isham, C., Evans, D. and Firth, A. (2007) 'What do specialists do in CPD programmes for which there is evidence of positive outcomes for pupils and teachers?' Report. In: Research Evidence in Education Library. London: EPPI-Centre, Social Science Research Unit, Institute of Education, University of London. Summary available at: http://www.eppi.ioe.ac.uk/cms/Default.aspx?tabid=2275 (Accessed: 26 October 2017).

Daly, C. Pachler, N. and Pelletier, C. (2009) Continuing Professional Development in ICT for teachers: A literature review. London: WLE Centre, Institute of Education, University of London. Available at: http://discovery.ucl.ac.uk/10003183/ (Accessed: 26 October 2017).

DeSantis, N. (2012) 'Self-Described EduPunk Says Colleges Should Abandon Course Management Systems.' The Chronicle of Higher Education. Available at: http://www.chronicle.com/article/Self-Described-EduPunk-Says/130917 (Accessed: 28 October 2017).

Donnelly, R. and O'Rourke, K. C. (2007) 'What now? Evaluating eLearning CPD practice in Irish third-level education.' Journal of Further and Higher Education,31(1), 31-40. Available 
at: https://www.tandfonline.com/doi/abs/10.1080/03098770601167864 (Accessed: 26 September 2017).

Ecclesfield, N., Rebbeck, G. and Garnett, F. (2013) 'The Case Of The Curious And The Confident - The Untold Story Of Changing Teacher Attitudes To E-Learning And Technology In Action In The FE Sector.' Compass: Journal of Learning and Teaching, 3(5). Available at: https://journals.gre.ac.uk/index.php/compass/article/view/71 (Accessed: 26 September 2017).

Guskey, T. (2002) 'Professional development and teacher change.' Teachers and Teaching: theory and practice, 8(3), 381-391. Available at: https://www.tandfonline.com/doi/abs/10.1080/135406002100000512 (Accessed: 16 September 2017).

Hew, K.F. and Brush, T. (2007) 'Integrating technology into K-12 teaching and learning: Current knowledge gaps and recommendations for future research.' Educational Technology Research and Development, 55(3), 223-252. Available at: https://link.springer.com/article/10.1007/s11423-006-9022-5 (Accessed: 16 September 2017).

Hennessy, S., Ruthven, K. and Brindley, S. (2005) 'Teacher perspectives on integrating ICT into subject teaching: commitment, constraints, caution, and change.' Journal of Curriculum Studies, 37(2), 155-192. Available at:

https://www.tandfonline.com/doi/abs/10.1080/0022027032000276961 (Accessed: 16 September 2017).

Hughes, J. and Kidd, W. (not dated) Working with Diverse Groups of Learners in the Digital Age. Escalate. Available at: http://escalate.ac.uk/downloads/8642.pdf (Accessed: 21 May 2017).

Kennedy, A. (2011) 'Collaborative continuing professional development (CPD) for teachers in Scotland: aspirations, opportunities and barriers.' European Journal of Teacher Education, 34(1), 25-41. Available at: https://www.tandfonline.com/doi/abs/10.1080/02619768.2010.534980 (Accessed: 21 May 2017).

Koehler, M. and Mishra, P. (2009) 'What is technological pedagogical content knowledge (TPACK)?' Contemporary issues in technology and teacher education, 9(1), 60-70.

Available at: http://www. citejournal.org/volume-9/issue-1-09/general/what-is-technologicalpedagogicalcontent-knowledge (Accessed: 21 May 2017).

Newman, T and Beetham, H. (2017) Student Digital Experience Tracker 2017: the voices of 22,000 UK learners. Bristol: Jisc. Available at: http://repository.jisc.ac.uk/6662/1/Jiscdigitalstudenttracker2017.pdf (Accessed: 21 May 2017).

Oblinger, D. (2012) Game changers education and information technologies. United States: Educause. Available at: https://www.educause.edu/research-and-publications/books/gamechangers-education-and-information-technologies (Accessed: 21 June 2017). 
Rogers, E. (2003) Diffusion of Innovations. New York: Free Press.

Romiszowski, A.J. (2004) 'How's the e-learning baby? Factors leading to success or failure of an educational technology innovation.' Educational Technology, 44 (1), 5-27. Available at: http://asianvu.com/digital-library/elearning/elearning failure study-romiszowsky.pdf (Accessed: 21 June 2017).

Rowan, C. (2014) Five Arguments for the Restriction of Education Technology in Elementary School Settings. Available at: http://www.zonein.ca/zoneinworkshop/articles/fivearguments-for-the-elimination-of-education-technology-in-elementary-school-settings/ (Accessed: 22 May 2017).

Walker, R., Voce, J., Nicholls, J., Swift, E., Ahmed, J., Horrigan, S. and Vincent, P. (2016) Survey of Technology Enhanced Learning for Higher Education in the UK. Oxford: Universities and Colleges Information Systems Association (UCISA). Available at: https://www.ucisa.ac.uk/bestpractice/surveys/tel/tel (Accessed: 21 October 2017). 